Check for updates

Cite this: Phys. Chem. Chem. Phys., 2018, 20, 5501

Received 8th September 2017, Accepted 31st October 2017

DOI: $10.1039 / c 7 c p 06131 \mathrm{e}$

rsc.li/pccp

\section{Theoretical investigation of the infrared spectrum of small polyynes $\dagger$}

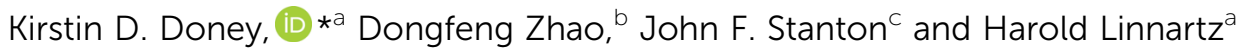

The full cubic and semidiagonal quartic force fields of acetylene $\left(\mathrm{C}_{2} \mathrm{H}_{2}\right)$, diacetylene $\left(\mathrm{C}_{4} \mathrm{H}_{2}\right)$, triacetylene $\left(\mathrm{C}_{6} \mathrm{H}_{2}\right)$, and tetraacetylene $\left(\mathrm{C}_{8} \mathrm{H}_{2}\right)$ are determined using $\operatorname{CCSD}(\mathrm{T})$ (coupled cluster theory with single and double excitations and augmented by a perturbative treatment of triple excitations) in combination with the atomic natural orbital (ANO) basis sets. Application of second-order vibrational perturbation theory (VPT2) results in vibrational frequencies that agree well with the known fundamental and combination band experimental frequencies of acetylene, diacetylene, and triacetylene (average discrepancies are less than $\left.10 \mathrm{~cm}^{-1}\right)$. Furthermore, the predicted ground state rotational constants $\left(B_{0}\right)$ and vibration-rotation interaction constants $\left(\alpha_{i}\right)$ are shown to be consistent with known experimental values. New vibrational frequencies and rotational parameters from the presented theoretical predictions are given for triacetylene and tetraacetylene, which can be used to aid laboratory and astronomical spectroscopic searches for characteristic transitions of these molecules.

\section{Introduction}

Due to their reactive nature, unsaturated linear hydrocarbons, such as acetylene and polyynes (general structure $\mathrm{HC}_{2 n} \mathrm{H} ; \mathrm{X}^{1} \Sigma_{\mathrm{g}}{ }^{+}$), are prevalent in combustion chemistry, ${ }^{1-4}$ plasma processes, ${ }^{5,6}$ chemical synthesis, ${ }^{7-10}$ chemistry of planetary atmospheres, ${ }^{11-19}$ and interstellar gas-phase chemistry. ${ }^{20-25}$ They are of particular interest for astronomers, because they are believed to act as the ultraviolet (UV) shield in hydrocarbon-rich atmospheres, ${ }^{26-29}$ and in the formation and destruction of polycyclic aromatic hydrocarbons (PAHs), ${ }^{18,30-33}$ a major reservoir of carbon in the universe. In astronomical environments, the formation of long chain polyynes from acetylene is believed to occur through polymerization reactions, ${ }^{19,34,35}$

$$
\begin{gathered}
\mathrm{HC}_{2 n} \mathrm{H}+\mathrm{C}_{2} \mathrm{H} \rightarrow \mathrm{HC}_{2 n+2} \mathrm{H}+\mathrm{H}, \\
\mathrm{HC}_{2} \mathrm{H}+\mathrm{C}_{2 n} \mathrm{H} \rightarrow \mathrm{HC}_{2 n+2} \mathrm{H}+\mathrm{H}, \\
\mathrm{HC}_{2 n} \mathrm{H}^{+}+\mathrm{HC}_{2} \mathrm{H} \rightarrow \mathrm{HC}_{2 n+2} \mathrm{H}_{2}^{+}+\mathrm{H}, \\
\mathrm{HC}_{2 n+2} \mathrm{H}_{2}^{+}+\mathrm{e}^{-} \rightarrow \mathrm{HC}_{2 n+2} \mathrm{H}+\mathrm{H} .
\end{gathered}
$$

\footnotetext{
${ }^{a}$ Sackler Laboratory for Astrophysics, Leiden Observatory, Leiden University, Leiden, The Netherlands. E-mail: doney@strw.leidenuniv.nl; Tel: +31 (0)71 5278413

${ }^{b}$ CAS Center for Excellence in Quantum Information and Quantum Physics and Hefei National Laboratory for Physical Sciences at the Microscale,

University of Science and Technology of China, Hefei, Anhui, P. R. China

${ }^{c}$ Department of Chemistry, University of Florida, Gainesville, Florida, USA

$\dagger$ Electronic supplementary information (ESI) available. See DOI: 10.1039/ c7cp06131e
}

Although long carbon chain molecules (e.g., $\mathrm{HC}_{n}$ and $\mathrm{HC}_{n} \mathrm{~N}$ for $n \leq 9)^{36-39}$ and small polyynes $\left(\mathrm{HC}_{2 n} \mathrm{H}\right.$ for $\left.n \leq 3\right)$ have been detected in carbon-rich astronomical sources, ${ }^{20,21,39}$ tetraacetylene has yet to be observed. One limiting factor is that as centrosymmetric molecules, polyynes lack a permanent dipole moment, and cannot be detected by radioastronomy using pure rotational transitions, unlike, e.g., $\mathrm{HC}_{n} \mathrm{~N}$. Therefore, ro-vibrational spectra in the infrared (IR) region are the most important spectroscopic tools to detect polyynes both in the laboratory and in space. In particular, detection of acetylene, diacetylene, and triacetylene in planetary atmospheres and protoplanetary nebulae has been realized primarily through observation of the strongest perpendicular band $\left(\nu_{5}, \nu_{8}\right.$, and $\nu_{11}$, respectively, at $\sim 13-17 \mu \mathrm{m}$ ) and the second strongest parallel band $\left(\nu_{4}+\nu_{5}, \nu_{6}+\nu_{8}\right.$, and $\nu_{8}+\nu_{11}$, respectively, at $\left.\sim 8 \mu \mathrm{m}\right) .{ }^{11,12,20,21}$ However, accurate line positions for tetraacetylene are lacking, from either laboratory or theoretical studies.

Extensive theoretical and experimental studies have been carried out for acetylene and diacetylene in the past few decades, including high-resolution spectroscopic studies of all the fundamental bands and a significant number of the combination bands, ${ }^{29,40-50}$ and high level ab initio calculations that take into account anharmonic effects. ${ }^{51-54}$ The combination of these studies shows that current quantum chemical theory, particularly coupled cluster theory with single and double excitations and augmented by a perturbative treatment of triple excitations $(\operatorname{CCSD}(\mathrm{T})),{ }^{55}$ is able to accurately reproduce equilibrium geometries, experimental vibrational frequencies, vibration-rotation interaction constants $\left(\alpha_{i}\right)$, and ground state rotational constants $\left(B_{0}\right)$. 
Triacetylene and tetraacetylene are not as thoroughly studied, notably in terms of rotational information. While all of the fundamental vibrational modes of triacetylene have been measured, there is only rotational information for the IR active fundamental modes, ${ }^{56}$ and the strongest IR combination band $\left(\nu_{8}+\nu_{11}\right) \cdot{ }^{57-61}$ However, theoretical studies of triacetylene do give rotational information for the remaining modes from $\operatorname{CCSD}(\mathrm{T})$ calculations of the vibration-rotation interaction constants $^{62}$ and the equilibrium geometry. ${ }^{63}$ In addition, the harmonic frequencies of triacetylene were calculated using partial fourth-order many-body perturbation theory [SDQ-MBPT(4)]. ${ }^{63}$ Conversely though, to the authors' knowledge, there is almost no rotational information for tetraacetylene. There has been only one low-resolution spectroscopic study of tetraacetylene, which measured three of the fundamentals $\left(\nu_{6}, \nu_{8}\right.$, and $\nu_{14}$ at 3329.4, 2023.3 , and $621.5 \mathrm{~cm}^{-1}$, respectively), and one combination band $\left(\nu_{10}+\nu_{14}\right.$ at $\left.1229.7 \mathrm{~cm}^{-1}\right)$, and gives an estimate for the electronic ground state rotational constant, $B_{0} \cdot{ }^{64}$ Unfortunately, the theoretical knowledge of tetraacetylene is equally limited, with only two studies of the equilibrium geometry (at the Hartree-Fock ${ }^{65}$ and $\mathrm{B} \mathrm{LYP}^{66}$ level of theory), and a calculation of the harmonic vibrational frequencies at the SVWN level of theory. ${ }^{64}$ While the two modes that are most useful for astronomical identification $\left(\nu_{14}\right.$ and $\left.\nu_{10}+\nu_{14}\right)$ were measured, the uncertainty associated with the line positions is too large to allow for an unambiguous assignment. Moreover, some high-resolution IR searches have been attempted, ${ }^{50,61,62,67}$ but so far no transitions have been assigned to tetraacetylene.

In this paper, we report the $a b$ initio calculations for acetylene, diacetylene, triacetylene, and tetraacetylene. Due to the centrosymmetric nature of these molecules, observations in the laboratory and in space are most easily accomplished through their infrared spectra. As such, the properties computed and presented here are those related to that technique: fundamental vibrational frequencies, ground state rotational constants, and intramolecular interactions. The computational approach is calibrated using the well studied acetylene and diacetylene, and then extended to make predictions for triacetylene and tetraacetylene.

\section{Computational methods}

All calculations were carried out at the $\operatorname{CCSD}(\mathrm{T})$ level of theory, which with a sufficiently large basis set has been shown to accurately reproduce experimental values of semi-rigid molecules. ${ }^{52-55,68-72}$ Equilibrium geometries were determined using the large core-valence correlation-consistent quadruple- $\zeta$ basis set (cc-pCVQZ), which features [8s7p5d3f1g] (nonhydrogen atoms) and [4s3p2d1f] (hydrogen) of (15s9p5d3f1g) and (6s3p2d1f) primitive basis sets, respectively. ${ }^{73-75}$ All electron $(\mathrm{AE})-\mathrm{CCSD}(\mathrm{T}) / \mathrm{cc}-\mathrm{pCVQZ}$ has been shown to give very accurate equilibrium geometries for unsaturated hydrocarbons. ${ }^{54,76-78}$ Optimizations were done using analytic energy derivatives, ${ }^{79}$ and were considered converged when the root-mean-square (RMS) gradient fell below $10^{-10}$ au.
However, it is well known that correlation-consistent basis sets, such as cc-pCVQZ, tend to underestimate the vibrational frequencies of symmetric bending modes $\left(\pi_{\mathrm{g}}\right)$ of conjugated molecules, e.g., polyynes, due to their susceptibility to an intramolecular variant of basis set superposition error (BSSE). ${ }^{54,80}$ It has been shown that one way to avoid this problem is to use basis sets with a large number of Gaussian primitives (particularly f-type), such as the atomic natural orbital (ANO) basis set (with the primitive basis set (13s8p6d4f2g) for non-hydrogen atoms and (8s6p4d2f) for hydrogen). ${ }^{52,81,82}$ The basis set has two common truncations: [4s3p2d1f] for nonhydrogen atoms and [4s2p1d] for hydrogen (hereafter known as ANO1), and [5s4p3d2f1g] (non-hydrogen atoms) and [4s3p2d1f] (hydrogen) (hereafter known as ANO2). ${ }^{74,75,81}$ In addition, only the valence electrons of carbon are considered in the correlation treatment, i.e., standard frozen-core (fc) calculations. (fc)-CCSD(T)/ ANO1 has been shown to accurately reproduce experimental frequencies and intensities for small molecules. ${ }^{52,83,84}$ Using the (fc)-CCSD(T)/ANO1 optimized geometry, second-order vibrational perturbation (VPT2) theory calculations were determined from full cubic and the semidiagonal part of the quartic force fields obtained by numerical differentiation of analytic $\operatorname{CCSD}(\mathrm{T})$ second derivatives. ${ }^{70,85}$ All calculations were performed with the development version of the CFOUR program. ${ }^{86}$

\section{Results and discussion}

\subsection{Equilibrium structure}

The AE-CCSD(T)/cc-pCVQZ equilibrium geometries are shown in Fig. 1, with comparison to experimentally derived values (in italics) when known. ${ }^{53,87,88}$ The theoretical equilibrium bond lengths for acetylene, diacetylene, and triacetylene all agree within $0.5 \%$ of the structures determined from experimentally measured rotational constants. As the length of the carbon chain increases, the $\mathrm{C}-\mathrm{H}$ bond lengths stay essentially the same, $\sim 1.062 \AA$, consistent with a sp-H type $\mathrm{C}-\mathrm{H}$ bond. However, the $\mathrm{C} \equiv \mathrm{C}$ bond lengths increase (particularly the internal $\mathrm{C} \equiv \mathrm{C}$ bonds), while the $\mathrm{C}-\mathrm{C}$ bond lengths decrease, becoming closer to that typical of CC double bonds. This suggests that the $\pi$ electrons become more delocalized over the internuclear axis, and the polyyne's configuration moves from a strict triple-single bond alternation to more of a consecutive

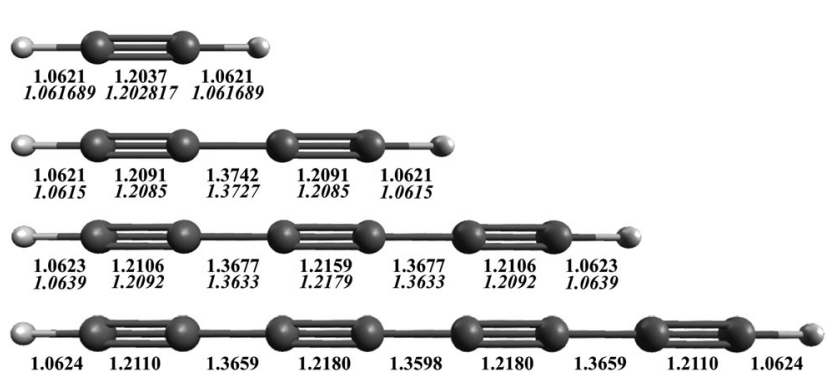

Fig. 1 AE-CCSD(T)/cc-pCVQZ equilibrium geometries (Å) for $\mathrm{HC}_{2 n} \mathrm{H}$. Experimentally determined equilibrium bond lengths for acetylene, ${ }^{87}$ diacetylene, ${ }^{53}$ and triacetylene ${ }^{88}$ are given in italics below. 
Table $1 \mathrm{CCSD}(\mathrm{T}) / \mathrm{ANO} 1$ rotational constants (in $\mathrm{cm}^{-1}$ ) of acetylene, diacetylene, triacetylene, and tetraacetylene

\begin{tabular}{lllll}
\hline & $\mathrm{HC}_{2} \mathrm{H}$ & $\mathrm{HC}_{4} \mathrm{H}$ & $\mathrm{HC}_{6} \mathrm{H}$ & $\mathrm{HC}_{8} \mathrm{H}$ \\
\hline Calc. & & & & \\
$B_{\mathrm{e}}$ & 1.181053 & 0.146248 & 0.044064 & 0.018823 \\
$B_{0}$ & 1.175319 & 0.146167 & 0.044092 & 0.018844 \\
$D_{\mathrm{e}}\left(\times 10^{8}\right)$ & 160 & 1.5 & 0.086 & 0.012
\end{tabular}

Expt.

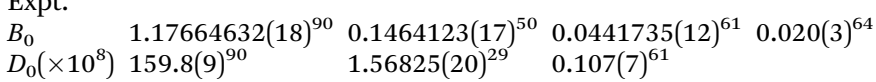

double bond character of the CC bonds, making the overall structure more rigid as $\mathrm{C}_{2}$ units are added, an effect that also qualitatively acts to increase the biradical character of the molecule as the size grows.

The equilibrium rotational constants, $\mathrm{B}_{e}$, obtained from the $\operatorname{AE}-\mathrm{CCSD}(\mathrm{T}) / \mathrm{cc}-\mathrm{pCVQZ}$ equilibrium geometries are summarized in Table 1, and agree well with experimental ground state rotational constants $\left(B_{0}\right)$. As such, the equilibrium rotational constants suggest that the calculations predict the correct ground state geometry, because for linear molecules with more than three atoms the summation of vibration-rotation interaction constants $\left(\alpha_{i}\right)$ is expected to be close to zero, and from

$$
B_{0}=B_{\mathrm{e}}-\frac{1}{2} \sum_{i} \alpha_{i},
$$

$B_{0} \sim B_{\mathrm{e}}$.

In addition, as seen for other carbon chains (e.g., $\mathrm{HC}_{n}$, $\mathrm{HC}_{2 n+1} \mathrm{~N}$, and $\left.\mathrm{H}_{2} \mathrm{C}_{n}\right)^{89}$ the centrifugal distortion constant $\left(D_{\mathrm{e}}\right)$ decreases with increasing molecular size, with a theoretical $D_{\mathrm{e}}=1.6 \times 10^{-6} \mathrm{~cm}^{-1}$ for acetylene, $D_{\mathrm{e}}=1.5 \times 10^{-8} \mathrm{~cm}^{-1}$ for diacetylene, $D_{\mathrm{e}}=8.6 \times 10^{-10} \mathrm{~cm}^{-1}$ for triacetylene, and $D_{\mathrm{e}}=1.2 \times 10^{-10} \mathrm{~cm}^{-1}$ for tetraacetylene. These values are consistent with those found experimentally for the respective vibrational ground states (Table 1). As noted by Thaddeus et al. ${ }^{89}$ this behavior of increasing stiffness with chain length is a distinguishing characteristic associated with bona fide chains.

\subsection{Spectroscopic properties of acetylene and diacetylene}

The quality of the present calculations is checked by comparison to the experimentally well studied acetylene and diacetylene. The harmonic and VPT2 fundamental frequencies of the fundamental and combination bands are given in Table 2 and 3 for acetylene and diacetylene, respectively, and experimental values are included for comparison. The (fc)-CCSD(T)/ANO1 VPT2 fundamental frequencies show good agreement with experimental values, with most observed-calculated deviations $(\mathrm{o}-\mathrm{c})$ being less than $5 \mathrm{~cm}^{-1}$ and all being less than $15 \mathrm{~cm}^{-1}$.

Based on previous studies of acetylene ${ }^{52}$ and diacetylene, ${ }^{53}$ the use of the ANO2 basis set was evaluated compared to the ANO1 basis set. For some of the vibrational modes, such as the $\nu_{4}$ mode of acetylene $\left[612.88 \mathrm{~cm}^{-1}\right.$ (observed),${ }^{42}$ Martin et al. ${ }^{52}$ showed that $\mathrm{CCSD}(\mathrm{T}) / \mathrm{ANO} 2$ can give a slightly better agreement (o-c value of $\sim 2 \mathrm{~cm}^{-1}$ ) compared to the ANO1 basis set (o-c value of $\sim 12 \mathrm{~cm}^{-1}$ ). However, the study by Thorwirth et al. ${ }^{53}$
Table 2 Harmonic and anharmonic (VPT2) frequencies (in $\mathrm{cm}^{-1}$ ) of acetylene fundamental and selected combination bands

\begin{tabular}{|c|c|c|c|}
\hline & \multicolumn{2}{|c|}{$\mathrm{CCSD}(\mathrm{T}) / \mathrm{ANO}^{a}{ }^{a}$} & \multirow{2}{*}{$\frac{\text { Experimental }}{\nu}$} \\
\hline & $\omega$ & $\nu$ & \\
\hline$\nu_{1}\left(\sigma_{g}^{+}\right)$ & $3514.2(0)$ & $3375.2(0)$ & $3372.851^{41}$ \\
\hline$\nu_{2}\left(\sigma_{\mathrm{g}}^{+}\right)$ & $2001.5(0)$ & $1964.8(0)$ & $1974.317^{41}$ \\
\hline$\nu_{3}\left(\sigma_{\mathrm{u}}^{+}\right)$ & $3414.6(84.7)$ & $3285.9(74.8)$ & $3288.58075^{48}$ \\
\hline$\nu_{4}\left(\pi_{\mathrm{g}}\right)$ & $600.5(0)$ & $600.6(0)$ & $612.871^{42}$ \\
\hline$\nu_{5}\left(\pi_{\mathrm{u}}\right)$ & $752.3(90.5)$ & $734.7(91.7)$ & $730.332^{42}$ \\
\hline$\nu_{4}+\nu_{5}\left(\sigma_{u}^{+}\right)$ & 1352.8 & $1329.2(10.8)$ & $1328.074^{42}$ \\
\hline$\nu_{2}+\nu_{5}\left(\pi_{\mathrm{u}}\right)$ & 2753.8 & $2698.3(0.1)$ & $2701.907^{43}$ \\
\hline$\nu_{3}+\nu_{4}\left(\pi_{\mathrm{u}}\right)$ & 4015.1 & $3878.5(0.5)$ & $3882.4060^{41}$ \\
\hline$\nu_{1}+\nu_{5}\left(\pi_{\mathrm{u}}\right)$ & 4266.5 & $4098.9(0.5)$ & $4091.17326^{91}$ \\
\hline$\nu_{1}+\nu_{3}\left(\sigma_{\mathrm{u}}^{+}\right)$ & 6928.7 & $6551.9(2.0)$ & $6556.46^{40}$ \\
\hline \multicolumn{4}{|c|}{ Anharmonic $\mathrm{ZPE}=5760.1$} \\
\hline
\end{tabular}

${ }^{a}$ Intensities in $\mathrm{km} \mathrm{mol}^{-1}$ are given in parentheses.

Table 3 Harmonic and anharmonic (VPT2) frequencies (in $\mathrm{cm}^{-1}$ ) of diacetylene fundamental and selected combination bands

\begin{tabular}{|c|c|c|c|}
\hline & \multicolumn{2}{|c|}{$\mathrm{CCSD}(\mathrm{T}) / \mathrm{ANO}^{a}{ }^{a}$} & \multirow{2}{*}{$\frac{\text { Experimental }}{\nu}$} \\
\hline & $\omega$ & $\nu$ & \\
\hline$\nu_{1}\left(\sigma_{\mathrm{g}}^{+}\right)$ & $3465.8(0)$ & $3332.5(0)$ & $3332.15476^{46}$ \\
\hline$\nu_{2}\left(\sigma_{\mathrm{g}}^{+}\right)$ & $2240.2(0)$ & 2193.1(0) & $2188.9285^{44}$ \\
\hline$\nu_{3}\left(\sigma_{\mathrm{g}}^{+}\right)$ & $891.1(0)$ & $859.2(0)$ & $871.9582^{44}$ \\
\hline$\nu_{4}\left(\sigma_{\mathrm{u}}^{+}\right)$ & $3465.9(152.7)$ & $3333.1(135.5)$ & $3333.6634^{50}$ \\
\hline$\nu_{5}\left(\sigma_{\mathrm{u}}^{+}\right)$ & $2054.1(0.2)$ & $2016.9(0.5)$ & $2022.2415^{44}$ \\
\hline$\nu_{6}\left(\pi_{\mathrm{g}}\right)$ & $636.3(0)$ & $624.2(0)$ & $625.643507^{29}$ \\
\hline$\nu_{7}\left(\pi_{\mathrm{g}}\right)$ & 479.8(0) & $476.9(0)$ & $482.7078^{44}$ \\
\hline$\nu_{8}\left(\pi_{\mathrm{u}}^{\circ}\right)$ & $636.3(78.7)$ & $624.1(78.8)$ & $628.040776^{29}$ \\
\hline$\nu_{9}\left(\pi_{\mathrm{u}}\right)$ & $220.7(7.3)$ & $219.6(7.3)$ & $219.97713^{47}$ \\
\hline $2 \nu_{9}\left(\sigma_{\mathrm{g}}^{+}\right)$ & 441.4 & $438.5(0)$ & $438.47757^{47}$ \\
\hline$\nu_{7}+\nu_{9}\left(\sigma_{\mathrm{u}}^{+}\right)$ & 700.5 & $696.3(0.8)$ & $701.8939^{29}$ \\
\hline$\nu_{6}+\nu_{9}\left(\sigma_{\mathrm{u}}^{+}\right)$ & 857.0 & $843.9(0.01)$ & $845.655513^{29}$ \\
\hline$\nu_{8}+\nu_{9}\left(\sigma_{g}^{+}\right)$ & 857.0 & $843.9(0)$ & $848.365918^{29}$ \\
\hline$\nu_{7}+\nu_{8}\left(\pi_{\mathrm{u}}^{\circ}\right)$ & 1116.1 & $1103.1(0.6)$ & $1111^{45}$ \\
\hline$\nu_{6}+\nu_{8}\left(\sigma_{\mathrm{u}}^{+}\right)$ & 1272.6 & $1244.7(21.8)$ & $1241.060828^{46}$ \\
\hline $2 \nu_{6}+\nu_{8}\left(\pi_{\mathrm{u}}\right)$ & 1909.0 & $1864.6(0.0)$ & $1863.2512^{44}$ \\
\hline$\nu_{2}+\nu_{9}\left(\pi_{\mathrm{u}}\right)$ & 2460.9 & $2410.0(0.04)$ & $2406.4251^{44}$ \\
\hline$\nu_{5}+\nu_{7}\left(\pi_{\mathrm{u}}\right)$ & 2533.9 & $2489.0(0.01)$ & $2500.6458^{44}$ \\
\hline$\nu_{5}+\nu_{6}\left(\pi_{\mathrm{u}}\right)$ & 2690.4 & $2637.0(0.04)$ & $2643.32323^{46}$ \\
\hline$\nu_{2}+\nu_{8}\left(\pi_{\mathrm{u}}\right)$ & 2876.6 & $2810.9(0.4)$ & $2805^{45}$ \\
\hline$\nu_{1}+\nu_{9}\left(\pi_{\mathrm{u}}\right)$ & 3686.5 & $3551.6(0.1)$ & $3551.56158159^{46}$ \\
\hline$\nu_{1}+\nu_{8}\left(\pi_{\mathrm{u}}\right)$ & 4102.1 & $3946.9(0.7)$ & $3939^{45}$ \\
\hline$\nu_{4}+\nu_{6}\left(\pi_{\mathrm{u}}\right)$ & 4102.3 & $3947.8(0.7)$ & \\
\hline$\nu_{2}+\nu_{5}\left(\sigma_{\mathrm{u}}^{+}\right)$ & 4294.3 & $4194.0(0.1)$ & \\
\hline$\nu_{4}+\nu_{3}\left(\sigma_{\mathrm{u}}^{+}\right)$ & 4357.0 & $4192.3(0.1)$ & \\
\hline$\nu_{1}+\nu_{4}\left(\sigma_{\mathrm{u}}^{+}\right)$ & 6931.7 & $6557.2(3.4)$ & $6565.472^{49}$ \\
\hline \multicolumn{4}{|c|}{ Anharmonic ZPE = 7966.9} \\
\hline
\end{tabular}

showed that, for diacetylene, the average $\mathrm{O}-\mathrm{c}$ value with $\operatorname{CCSD}(\mathrm{T}) / \mathrm{ANO} 2$ is comparable to that for the ANO1 basis set ( $\sim 6 \mathrm{~cm}^{-1}$ and $\sim 4 \mathrm{~cm}^{-1}$, respectively). Moreover, the time cost of (fc)-CCSD(T)/ANO2 calculations compared to (fc)-CCSD(T)/ ANO1 far outweighs the minor frequency differences, and does not justify the higher computational cost of the ANO2 basis set in predicting the fundamental frequencies of longer polyynes.

The (fc)-CCSD(T)/ANO1 anharmonicity constants $\left(x_{i j}\right.$, ESI $\dagger$ ) also accurately account for the known combination bands of acetylene and diacetylene (Tables 2 and 3, respectively). All the combination bands are within $5 \mathrm{~cm}^{-1}$ of their observed values. For both acetylene and diacetylene, the ANO1 basis set is able 
to most accurately reproduce the $\mathrm{C}-\mathrm{H}$ asymmetric stretch mode $\left(\nu_{3}\right.$ and $\nu_{4}$, respectively). Significant is the agreement between the experimental and our predicted frequencies of $\nu_{6}+\nu_{8}$ [1241.060828(38) $\mathrm{cm}^{-1}$ (observed) ${ }^{46}$ and $1244.7 \mathrm{~cm}^{-1}$ (theoretical)], and $2 \nu_{6}+\nu_{8}\left[1863.2512(5) \mathrm{cm}^{-1}\right.$ (observed) ${ }^{44}$ and $1864.6 \mathrm{~cm}^{-1}$ (theoretical)] of diacetylene; both of which had only previously been calculated with $\operatorname{CCSD}(\mathrm{T}) / \mathrm{cc}-\mathrm{pCVQZ}$, and had $\mathrm{o}-\mathrm{c}$ values greater than $20 \mathrm{~cm}^{-1} .{ }^{54}$ This suggests that the combination band VPT2 frequencies of polyynes determined using (fc)-CCSD(T)/ ANO1 are accurate to aid identification of molecules, such as in astronomical surveys.

The vibration-rotation interaction constants (Table 4) are also determined in the course of the VPT2 calculation, and are in good agreement with both previous theoretical studies ${ }^{52,54}$ and experimentally determined values. ${ }^{29,44,46,50,51,54}$ Based on the vibration-rotation interaction constants, the ground state rotational constants $\left(B_{0}\right)$ were determined using the $\operatorname{AE}-\operatorname{CCSD}(\mathrm{T}) /$ cc-pCVQZ determined $B_{\mathrm{e}}$ values (Table 1). For acetylene, $B_{0}=1.175319 \mathrm{~cm}^{-1}$, which is a $0.1 \%$ difference compared to the experimentally determined value of $B_{0}=1.17664632(18) \mathrm{cm}^{-1} \cdot{ }^{90}$ Diacetylene shows a similar $0.2 \%$ difference between the theoretical value of $B_{0}=0.146167 \mathrm{~cm}^{-1}$, and the experimentally determined value of $B_{0}=0.1464123(17) \mathrm{cm}^{-1} .{ }^{50}$ The consistent accuracy of these values suggests that the method presented is clearly good enough to be extrapolated to and aid high-resolution infrared spectroscopic searches for the larger polyynes.

\subsection{Spectroscopic properties of triacetylene}

The (fc)-CCSD(T)/ANO1 harmonic and VPT2 fundamental frequencies along with the experimental frequencies are given in Table 5. Comparison between theoretical VPT2 frequencies and experimental fundamentals measured with high-resolution techniques shows average $\mathrm{o}-\mathrm{c}$ values that are smaller than those seen for acetylene or diacetylene $\left(\mathrm{O}-\mathrm{c} \sim 2 \mathrm{~cm}^{-1}\right)$. For the known combination band, the (fc)-CCSD(T)/ANO1 anharmonicity

Table 4 CCSD(T)/ANO1 vibration-rotation interaction constants $\left(\alpha_{i}\right.$, in $\left.\mathrm{cm}^{-1}\right)$ of acetylene, diacetylene, triacetylene, and tetraacetylene. Experimental values are in parentheses

\begin{tabular}{llllc}
\hline Mode & $\begin{array}{l}\mathrm{HC}_{2} \mathrm{H} \\
\left(\times 10^{3}\right)\end{array}$ & $\begin{array}{l}\mathrm{HC}_{4} \mathrm{H} \\
\left(\times 10^{4}\right)\end{array}$ & $\begin{array}{l}\mathrm{HC}_{6} \mathrm{H} \\
\left(\times 10^{5}\right)\end{array}$ & $\begin{array}{l}\mathrm{HC}_{8} \mathrm{H} \\
\left(\times 10^{5}\right)\end{array}$ \\
\hline$\alpha_{1}$ & $6.853\left(6.904^{a}\right)^{51}$ & $2.157(2.153)^{50}$ & 2.97 & 0.730 \\
$\alpha_{2}$ & $6.007(6.181)^{51}$ & 6.608 & 15.20 & 4.91 \\
$\alpha_{3}$ & $5.800\left(5.882^{a}\right)^{51}$ & $3.123\left(3.110^{a}\right)^{54}$ & 7.44 & 2.55 \\
$\alpha_{4}$ & $-1.464(-1.354)^{51}$ & $2.139(2.183)^{50}$ & 3.82 & 3.76 \\
$\alpha_{5}$ & $-2.134(-2.232)^{51}$ & $3.938(3.948)^{44}$ & $2.99(3.58)^{61}$ & 0.930 \\
$\alpha_{6}$ & 0.730 & $-0.700(-0.678)^{29}$ & $9.91(9.15)^{58}$ & 0.730 \\
$\alpha_{7}$ & 4.06 & $-2.703(-2.711)^{46}$ & 9.91 & 4.06 \\
$\alpha_{8}$ & 2.33 & $-0.647(-0.636)^{29}$ & $-1.17(-1.071)^{58}$ & 2.33 \\
$\alpha_{9}$ & 2.05 & $-4.125(-4.183)^{46}$ & -5.83 & 2.05 \\
$\alpha_{10}$ & & & $-7.42(-7.88)^{58}$ & -0.295 \\
$\alpha_{11}$ & & & $-1.06(-1.06)^{57}$ & -1.95 \\
$\alpha_{12}$ & & & -5.07 & -1.69 \\
$\alpha_{13}$ & & & $-8.47(-8.7207)^{59}$ & -2.26 \\
$\alpha_{14}$ & & & & -0.295 \\
$\alpha_{15}$ & & & & -0.163 \\
$\alpha_{16}$ & & & & -2.29 \\
$\alpha_{17}$ & & & & -2.80 \\
$a_{1}$ & & & &
\end{tabular}

${ }^{a}$ Deperturbed.
Table 5 Harmonic and anharmonic (VPT2) frequencies (in $\mathrm{cm}^{-1}$ ) of triacetylene fundamental and selected combination bands

\begin{tabular}{|c|c|c|c|}
\hline & \multicolumn{2}{|c|}{$\mathrm{CCSD}(\mathrm{T}) / \mathrm{ANO}^{a}{ }^{a}$} & \multirow{2}{*}{$\frac{\text { Experimental }}{\nu}$} \\
\hline & $\omega$ & $\nu$ & \\
\hline \multicolumn{4}{|c|}{$3330.4(0)$} \\
\hline$\nu_{2}\left(\sigma_{\mathrm{g}}^{+}{ }^{+}\right)$ & $2284.0(0)$ & $2213.2(0)$ & $2201^{56}$ \\
\hline$\nu_{3}\left(\sigma_{\mathrm{g}}^{+}\right)$ & $2061.0(0)$ & $2023.2(0)$ & $2019^{56}$ \\
\hline$\nu_{4}\left(\sigma_{\mathrm{g}}^{+}\right)$ & $616.1(0)$ & $612.7(0)$ & $625^{56}$ \\
\hline$\nu_{5}\left(\sigma_{\mathrm{u}}^{+}\right)$ & 3463.1(126.4) & $3329.5(175.0)$ & $3329.0533^{61}$ \\
\hline$\nu_{6}\left(\sigma_{\mathrm{u}}^{+}\right)$ & $2172.2(0.0)$ & $2130.4(0.1)$ & $2128.91637^{58}$ \\
\hline$\nu_{7}\left(\sigma_{\mathrm{u}}^{+}\right)$ & $1169.6(1.7)$ & $1160.9(0.2)$ & $1115.0^{59}$ \\
\hline$\nu_{8}\left(\pi_{\mathrm{g}}\right)$ & $633.0(0)$ & $620.9(0)$ & $622.38^{57}$ \\
\hline$\nu_{9}\left(\pi_{\mathrm{g}}\right)$ & $489.5(0)$ & $486.2(0)$ & $491^{56}$ \\
\hline$\nu_{10}\left(\pi_{\mathrm{g}}\right)$ & $252.0(0)$ & $251.1(0)$ & $258^{56}$ \\
\hline$\nu_{11}\left(\pi_{\mathrm{u}}\right)$ & $632.0(80.5)$ & $619.9(83.2)$ & $621.34011^{60}$ \\
\hline$\nu_{12}\left(\pi_{\mathrm{u}}\right)$ & $444.7(1.0)$ & $441.8(1.0)$ & $443.5^{59}$ \\
\hline $\begin{array}{l}\nu_{13}\left(\pi_{\mathrm{u}}\right) \\
\nu_{\mathrm{g}}+\nu_{13}\left(\sigma_{\mathrm{u}}^{+}\right)\end{array}$ & $106.4(4.1)$ & $105.9(3.5)$ & $105.038616^{59}$ \\
\hline$\nu_{9}+\nu_{13}\left(\sigma_{\mathrm{u}}^{+}\right)$ & 595.9 & $591.7(0.8)$ & \\
\hline & 696.7 & $691.8(1.8)$ & \\
\hline $\begin{array}{l}\nu_{10}+\nu_{12}\left(\sigma_{\mathrm{u}}^{+}\right) \\
\nu_{8}+\nu_{12}\left(\sigma_{\mathrm{u}}^{+}\right)\end{array}$ & 1077.7 & 1063.5(0.3) & \\
\hline$\nu_{9}+\nu_{11}\left(\sigma_{\mathrm{u}}^{+}\right)$ & 1121.5 & 1107.1(0.7) & \\
\hline$\nu_{8}+\nu_{11}\left(\sigma_{\mathrm{u}}^{+}\right)$ & 1265.0 & $1237.4(31.4)$ & $1232.904295^{58}$ \\
\hline$\nu_{3}+\nu_{7}\left(\sigma_{\mathrm{u}}^{+}\right)$ & 3230.5 & $3182.8(0.1)$ & \\
\hline \multirow{2}{*}{$\begin{array}{l}\nu_{2}+\nu_{7}\left(\sigma_{\mathrm{u}}^{+}\right) \\
3 \nu_{7}\left(\sigma_{\mathrm{u}}^{+}\right)\end{array}$} & 3453.6 & $3362.2(2.5)$ & \\
\hline & 3508.7 & $3498.7(0.01)$ & \\
\hline$\nu_{1}+\nu_{13}\left(\pi_{\mathrm{u}}\right)$ & 3569.5 & $3436.1(0.2)$ & \\
\hline$\nu_{5}+\nu_{10}\left(\pi_{\mathrm{u}}\right)$ & 3715.1 & $3583.7(0.1)$ & \\
\hline $\begin{array}{l}\nu_{4}+\nu_{5}\left(\sigma_{\mathrm{u}}^{+}\right) \\
\nu_{1}+\nu_{11}\left(\pi_{\mathrm{u}}\right)\end{array}$ & 4079.3 & $3945.8(0.1)$ & \\
\hline$\nu_{1}+\nu_{11}\left(\pi_{\mathrm{u}}\right)$ & 4095.2 & $3940.1(0.8)$ & \\
\hline \multirow{2}{*}{$\begin{array}{l}\nu_{5}+\nu_{8}\left(\pi_{\mathrm{u}}\right)^{+} \\
\nu_{3}+\nu_{6}\left(\sigma_{\mathrm{u}}{ }^{+}\right)\end{array}$} & 4096.2 & $3943.9(0.8)$ & \\
\hline & 4233.1 & $4141.1(0.1)$ & \\
\hline & 4456.2 & 4334.7(0.1) & \\
\hline $\begin{array}{l}\nu_{2}+\nu_{6}\left(\sigma_{\mathrm{u}}^{+}\right) \\
\nu_{2}+\nu_{5}\left(\sigma_{\mathrm{u}}^{+}\right)\end{array}$ & 5747.2 & $5548.4(0.2)$ & \\
\hline$\nu_{1}+\nu_{5}\left(\sigma_{\mathrm{u}}^{+}\right)$ & 6926.3 & 6555.1(4.6) & \\
\hline \multicolumn{4}{|c|}{ Anharmonic $\mathrm{ZPE}=10095.8$} \\
\hline
\end{tabular}

constants $\left(x_{i j}, \mathrm{ESI} \dagger\right)$ are able to reproduce the experimental value to within $5 \mathrm{~cm}^{-1}$, suggesting other combination band frequencies are of equal accuracy.

For the modes observed in low-resolution studies (e.g., $\nu_{1}$ and $\nu_{12}$ ), the agreement is still good with $\mathrm{o}-\mathrm{c}$ values less than $20 \mathrm{~cm}^{-1}$. The notable exception is the internal $\mathrm{C} \equiv \mathrm{C}$ asymmetric stretch mode $\left(\nu_{7}\right)$, which differs by $45 \mathrm{~cm}^{-1}$. Since no rotationally resolved data can be found for this band, it is possible that the band observed at $1115.0 \mathrm{~cm}^{-159}$ was mis-assigned as the $\nu_{7}$ fundamental. A more likely assignment for this band is the $\nu_{9}+\nu_{11}$ combination band, which has a predicted VPT2 frequency of $1107.1 \mathrm{~cm}^{-1}$, a calculated intensity of $0.7 \mathrm{~km} \mathrm{~mol}^{-1}$, and the same symmetry. Furthermore, the combination band is expected to be $3.5 \times$ more intense than the $\nu_{7}$ fundamental at $0.2 \mathrm{~km} \mathrm{~mol}^{-1}$, suggesting that $\nu_{9}+\nu_{11}$ is more likely of the two to be observed. However, rotationally resolved measurements of this band are clearly needed to confirm this speculation.

We note that, a resonance between the $\nu_{5}$ fundamental and the $\nu_{2}+\nu_{7}$ and $3 \nu_{7}$ combination bands must be addressed to achieve the very small $\left(1 \mathrm{~cm}^{-1}\right) \mathrm{o}-\mathrm{c}$ difference obtained for the $\mathrm{C}-\mathrm{H}$ asymmetric stretch mode, $\nu_{5}$. The vibrational frequencies as a result of resonant interactions are calculated by a deperturbation-diagonalization technique followed by transformation of the deperturbed transition moments, as discussed 
Table 6 Harmonic and anharmonic (VPT2) frequencies (in $\mathrm{cm}^{-1}$ ) of tetraacetylene fundamental and selected combination bands

\begin{tabular}{|c|c|c|c|}
\hline & \multicolumn{2}{|c|}{$\operatorname{CCSD}(\mathrm{T}) / \mathrm{ANO}^{a}{ }^{a}$} & \multirow{2}{*}{$\frac{\text { Experimental }}{\nu}$} \\
\hline & $\omega$ & $\nu$ & \\
\hline$\nu_{1}\left(\sigma_{\mathrm{g}}^{+}\right)$ & $3462.0(0)$ & $3330.5(0)$ & \\
\hline$\nu_{2}\left(\sigma_{\mathrm{g}}^{+}\right)$ & $2263.2(0)$ & $2208.0(0)$ & \\
\hline$\nu_{3}\left(\sigma_{\mathrm{g}}^{+}\right)$ & $2134.6(0)$ & $2094.2(0)$ & \\
\hline$\nu_{4}\left(\sigma_{\mathrm{g}}^{+}\right)$ & $1296.4(0)$ & $1285.8(0)$ & \\
\hline$\nu_{5}\left(\sigma_{\mathrm{g}}^{+}\right)$ & $470.0(0)$ & $455.3(0)$ & \\
\hline$\nu_{6}\left(\sigma_{\mathrm{u}}^{+}\right)$ & $3461.6(223.1)$ & $3328.8(214.2)$ & $3329.4^{64}$ \\
\hline$\nu_{7}\left(\sigma_{\mathrm{u}}^{+}\right)$ & $2254.7(1.0)$ & $2227.6(0.5)$ & \\
\hline$\nu_{8}\left(\sigma_{\mathrm{u}}^{+}\right)$ & $2064.3(0.3)$ & $2026.6(0.6)$ & $2023.3^{64}$ \\
\hline$\nu_{9}\left(\sigma_{\mathrm{u}}^{+}\right)$ & $911.6(3.2)$ & $922.4(2.0)$ & \\
\hline$\nu_{10}\left(\pi_{\mathrm{g}}\right)$ & $632.4(0)$ & $620.0(0)$ & \\
\hline$\nu_{11}\left(\pi_{\mathrm{g}}\right)$ & $489.3(0)$ & $486.0(0)$ & \\
\hline$\nu_{12}\left(\pi_{\mathrm{g}}\right)$ & $422.3(0)$ & $419.5(0)$ & \\
\hline$\nu_{13}\left(\pi_{\mathrm{g}}\right)$ & $158.8(0)$ & $157.9(0)$ & \\
\hline$\nu_{14}\left(\pi_{\mathrm{u}}\right)$ & $632.6(79.6)$ & $619.7(79.9)$ & $621.5^{64}$ \\
\hline$\nu_{15}\left(\pi_{\mathrm{u}}\right)$ & $474.2(0.1)$ & $470.9(0.2)$ & \\
\hline$\nu_{16}\left(\pi_{\mathrm{u}}\right)$ & $267.7(3.2)$ & $266.7(3.1)$ & \\
\hline$\nu_{17}\left(\pi_{\mathrm{u}}\right)$ & $61.0(2.3)$ & $60.7(2.2)$ & \\
\hline$\nu_{11}+\nu_{17}\left(\sigma_{\mathrm{u}}^{+}\right)$ & 550.3 & 546.5(0.6) & \\
\hline$\nu_{13}+\nu_{15}\left(\sigma_{\mathrm{u}}^{+}\right)$ & 633.0 & $628.5(1.7)$ & \\
\hline$\nu_{12}+\nu_{16}\left(\sigma_{\mathrm{u}}^{+}\right)$ & 690.1 & $684.8(3.1)$ & \\
\hline$\nu_{12}+\nu_{15}\left(\sigma_{\mathrm{u}}^{+}\right)$ & 896.5 & $871.9(3.5)$ & \\
\hline$\nu_{11}+\nu_{15}\left(\sigma_{\mathrm{u}}^{+}\right)$ & 963.5 & $970.5(1.3)$ & \\
\hline$\nu_{10}+\nu_{15}\left(\sigma_{\mathrm{u}}^{+}\right)$ & 1106.6 & 1092.2(0.6) & \\
\hline$\nu_{10}+\nu_{14}\left(\sigma_{u}^{+}\right)$ & 1265.1 & $1236.7(37.5)$ & $1229.7^{64}$ \\
\hline$\nu_{2}+\nu_{9}\left(\sigma_{\mathrm{u}}^{+}\right)$ & 3174.8 & $3130.1(0.5)$ & \\
\hline$\nu_{4}+\nu_{8}\left(\sigma_{\mathrm{u}}^{+}\right)$ & 3360.7 & $3311.4(0.5)$ & \\
\hline$\nu_{6}+\nu_{10}\left(\pi_{\mathrm{u}}\right)$ & 4094.0 & 3939.1(0.8) & \\
\hline$\nu_{1}+\nu_{14}\left(\pi_{\mathrm{u}}\right)$ & 4094.6 & $3940.6(0.8)$ & \\
\hline$\nu_{1}+\nu_{6}\left(\sigma_{\mathrm{u}}^{+}\right)$ & 6923.6 & $6550.8(5.7)$ & \\
\hline \multicolumn{4}{|c|}{ Anharmonic ZPE $=12218.2$} \\
\hline
\end{tabular}

in the work of Vázquez and Stanton and Matthews et al. ${ }^{85}$ This combination of Fermi and Darling-Dennison interactions shifts the $\nu_{5}$ predicted frequency from 3333.1 to $3329.5 \mathrm{~cm}^{-1}$, which is able to reproduce the experimentally observed frequency [3329.0533(2) $\left.\mathrm{cm}^{-161}\right]$ with the same accuracy seen for diacetylene $\left(\mathrm{o}-\mathrm{c} \sim 0.5 \mathrm{~cm}^{-1}\right)$. The combination bands involved are similarly shifted: $\nu_{2}+\nu_{7}$ from 3329.5 to $3362.2 \mathrm{~cm}^{-1}$, and $3 \nu_{7}$ from 3526.7 to $3498.7 \mathrm{~cm}^{-1}$. Since the shift is most pronounced for the two combination bands, future experimental work to observe either of these bands is required to confirm this prediction.

The vibration-rotation interaction constants for triacetylene are given in Table 4, and are consistent with the previous $\operatorname{CCSD}(\mathrm{T}) / \mathrm{cc}-\mathrm{pCVQZ}$ theoretical study ${ }^{62}$ and experimentally determined values. ${ }^{57-59,61}$ Consequently, the calculated ground state rotational constant $B_{0}=0.044092 \mathrm{~cm}^{-1}$ is within $0.2 \%$ of the experimentally observed $B_{0}=0.0441735(12) \mathrm{cm}^{-1} \cdot{ }^{61}$

\subsection{Spectroscopic properties of tetraacetylene}

The (fc)-CCSD(T)/ANO1 harmonic and VPT2 frequencies of the fundamental and combination bands for tetraacetylene are given in Table 6, and the (fc)-CCSD(T)/ANO1 anharmonicity constants $\left(x_{i j}\right)$ are given in the ESI. $\dagger$ For the four experimentally observed bands, agreement of the observed and calculated frequencies is good at $7 \mathrm{~cm}^{-1}$, which is comparable to the uncertainty of the low resolution measurements. Furthermore, the ANO1 VPT2 frequencies are able to reproduce the experimental frequencies far better than the previous harmonic frequency calculations, which had o-c values of $\sim 20-100 \mathrm{~cm}^{-1} .{ }^{64}$ Of the predicted fundamental and combination bands, there are a number of bands that are found/predicted to have sufficient intensity and/or relatively unique frequency range that could offer viable target transitions to use to search for tetraacetylene in future laboratory or astronomical spectra. For example, in the IR the $\nu_{1}+\nu_{6}$ at $6550.8 \mathrm{~cm}^{-1}$ or $\nu_{12}+\nu_{15}$ at $871.9 \mathrm{~cm}^{-1}$ combination bands have both comparable predicted intensity to measured bands of di- and triacetylene, and have transitions in relatively clean regions of the spectrum. In terms of astronomical searches, the $\nu_{17}$ mode at $60.7 \mathrm{~cm}^{-1}$, offers a unique target transition, since its low frequency makes it accessible by far-IR observations, similar to the $\nu_{2}$ bending mode of $\mathrm{C}_{3} .{ }^{92}$

Based on the results discussed for the other small polyynes, the theoretical vibration-rotation interaction constants given in Table 4 are sufficient to assist in identification of ro-vibrational bands of tetraacetylene. The $\alpha_{i}$ results in a theoretical ground state rotational constant of $B_{0}=0.018844 \mathrm{~cm}^{-1}$ that agrees within errors with the experimentally determined value, $B_{0}=0.020(3) \mathrm{cm}^{-1} \cdot{ }^{64}$ Overall, for polyynes the difference between the experimental and calculated rotational constants $\left(\Delta B_{0}\right)$ decreases from 0.001 to $0.00008 \mathrm{~cm}^{-1}$ as the chain length is increased, which is consistent with the trend seen for other carbon chain molecules (e.g., $\left.\mathrm{HC}_{n} \mathrm{~N}, \mathrm{HC}_{n}, \mathrm{C}_{n} \mathrm{O}\right) .{ }^{93}$ Therefore, if the trend continues as expected then the $\Delta B_{0}$ for tetraacetylene is equal to or smaller than that seen for triacetylene, and the determined ground state rotational constant is a good approximation of the true value.

\section{Conclusions}

Accurate equilibrium geometries have been determined at the $\operatorname{AE}-\mathrm{CCSD}(\mathrm{T}) / \mathrm{cc}-\mathrm{pCVQZ}$ level of theory, and the full cubic and semidiagonal quartic force field have been determined at the (fc)-CCSD(T)/ANO1 level of theory for acetylene and the three smallest polyynes. No scaling or adjustments had to be included to match theoretical values with those determined by experiments. The resulting VPT2 fundamental vibrational frequencies and vibration-rotation interaction constants agree with known experimental values, showing about a $5 \mathrm{~cm}^{-1}$ deviation in frequencies for bands with high-resolution infrared information. For bands with only low-resolution data, the theoretical frequencies are able to confirm mode assignments or suggest a reassignment, as in the case of the observed band at $1115.0 \mathrm{~cm}^{-1}$ of triacetylene to the $\nu_{9}+\nu_{11}$ combination band, which has previously been attributed to the $\nu_{7}$ fundamental. The provisional $a b$ initio method used here is also able to accurately reproduce the observed frequencies of combination bands.

The calculated fundamental frequencies for triacetylene and tetraacetylene give insight as to why tetraacetylene has not yet been observed in space. Observation of centrosymmetric molecules in astronomical environments is mainly through infrared detection of the high intensity bending modes; e.g., $\nu_{8}\left[628.040776(36) \mathrm{cm}^{-1}\right]^{29}$ 
and $\nu_{6}+\nu_{8}\left[1241.060828(38) \mathrm{cm}^{-1}\right]^{46}$ of diacetylene, or $\nu_{11}$ $\left[621.34011(42) \mathrm{cm}^{-1}\right]^{60}$ and $\nu_{8}+\nu_{11}\left[1232.904295(74) \mathrm{cm}^{-1}\right]^{58}$ of triacetylene. However, the analogous modes for tetraacetylene are the $\nu_{14}\left[621.5(5) \mathrm{cm}^{-1}\right]^{64}$ and $\nu_{10}+\nu_{14}\left[1229.7(5) \mathrm{cm}^{-1}\right],{ }^{64}$ and are predicted to be significantly weaker in intensity due to lower column densities. ${ }^{34,35}$ Consequently, at these frequencies and resolutions of the previous infrared observations where polyynes were detected, ${ }^{20-22,24,25}$ the transitions of tetraacetylene are blended with those of triacetylene. Other bands of tetraacetylene would be more suitable for identification, such as $\nu_{1}+\nu_{6}, \nu_{12}+\nu_{15}$, or $\nu_{17}$ that are expected to be equally strong as bands already used to identify di- and triacetylene.

Overall, the resulting computed geometries lead to equilibrium rotational constants $\left(B_{\mathrm{e}}\right)$, which when corrected for vibrational zero-point effects give ground state equilibrium constants $\left(B_{0}\right)$ that agree with experimental values $(0.2 \%)$. Based on the small $\mathrm{o}-\mathrm{c}$ values for acetylene, diacetylene, and triacetylene, we are confident that the fundamental frequencies and spectroscopic constants determined here offer an accurate guide for spectroscopic searches focused on detection of ro-vibrational bands of triacetylene and tetraacetylene. Such work is underway in our laboratory.

\section{Conflicts of interest}

There are no conflicts to declare.

\section{Acknowledgements}

We thank Dr D. J. Nesbitt for helpful discussions. We acknowledge the financial support of the Netherlands Organization for Scientific Research (NWO) through a VICI grant, and the Netherlands Research School for Astronomy (NOVA). D. Z. also acknowledges financial support from the National Key R\&D Program of China (2017YFA0303502) and the Fundamental Research Funds for the Central Universities of China.

\section{References}

1 M. Frenklach, D. W. Clary, W. C. Gardiner and S. E. Stein, Symp. (Int.) Combust., [Proc.], 1985, 20, 887-901.

2 I. Cherchneff, J. R. Barker and A. G. G. M. Tielens, Astrophys. J., 1992, 401, 269-287.

3 K.-H. Homann, Angew. Chem., Int. Ed., 1998, 37, 2434-2451.

4 H. Richter, T. G. Benish, O. A. Mazyar, W. H. Green and J. B. Howard, Proc. Combust. Inst., 2000, 28, 2609-2618.

5 T. Fujii and M. Kareev, J. Appl. Phys., 2001, 89, 2543-2546.

6 H. Thejaswini, A. Majumdar, T. Tun and R. Hippler, Adv. Space Res., 2011, 48, 857-861.

7 H. Shirakawa, Rev. Mod. Phys., 2001, 73, 713-718.

8 X. Zhao, Y. Ando, Y. Liu, M. Jinno and T. Suzuki, Phys. Rev. Lett., 2003, 90, 187401.

9 A. Milani, M. Tommasini, M. Del Zoppo, C. Castiglioni and G. Zerbi, Phys. Rev. B: Condens. Matter Mater. Phys., 2006, 74, 153418.
10 T.-B. Ma, Y.-Z. Hu and H. Wang, J. Appl. Phys., 2008, 104, 064904.

11 V. G. Kunde, A. C. Aikin, R. A. Hanel, D. E. Jennings, W. C. Maguire and R. E. Samuelson, Nature, 1981, 292, 686-688.

12 T. de Graauw, H. Feuchtgruber, B. Bezard, P. Drossart, T. Encrenaz, D. A. Beintema, M. Griffin, A. Heras, M. Kessler, K. Leech, E. Lellouch, P. Morris, P. R. Roelfsema, M. Roos-Serote, A. Salama, B. Vandenbussche, E. A. Valentijn, G. R. Davis and D. A. Naylor, Astron. Astrophys., 1997, 321, L13-L16.

13 E. Wilson and S. Atreya, Planet. Space Sci., 2003, 51, 1017-1033.

14 V. G. Kunde, F. M. Flasar, D. E. Jennings, B. Bézard, D. F. Strobel, B. J. Conrath, C. A. Nixon, G. L. Bjoraker, P. N. Romani, R. K. Achterberg, A. A. Simon-Miller, P. Irwin, J. C. Brasunas, J. C. Pearl, M. D. Smith, G. S. Orton, P. J. Gierasch, L. J. Spilker, R. C. Carlson, A. A. Mamoutkine, S. B. Calcutt, P. L. Read, F. W. Taylor, T. Fouchet, P. Parrish, A. Barucci, R. Courtin, A. Coustenis, D. Gautier, E. Lellouch, A. Marten, R. Prangé, Y. Biraud, C. Ferrari, T. C. Owen, M. M. Abbas, R. E. Samuelson, F. Raulin, P. Ade, C. J. Césarsky, K. U. Grossman and A. Coradini, Science, 2004, 305, 1582-1587.

15 V. Vuitton, J.-F. Doussin, Y. Bénilan, F. Raulin and M.-C. Gazeau, Icarus, 2006, 185, 287-300.

16 M. Burgdorf, G. Orton, J. van Cleve, V. Meadows and J. Houck, Icarus, 2006, 184, 634-637.

17 V. S. Meadows, G. Orton, M. Line, M.-C. Liang, Y. L. Yung, J. Van Cleve and M. J. Burgdorf, Icarus, 2008, 197, 585-589.

18 J. H. Waite, D. T. Young, T. E. Cravens, A. J. Coates, F. J. Crary, B. Magee and J. Westlake, Science, 2007, 316, 870-875.

19 X. Gu, Y. S. Kim, R. I. Kaiser, A. M. Mebel, M. C. Liang and Y. L. Yung, Proc. Natl. Acad. Sci. U. S. A., 2009, 106, 16078-16083.

20 J. Cernicharo, A. M. Heras, J. R. Pardo, A. G. G. M. Tielens, M. Guélin, E. Dartois, R. Neri and L. B. F. M. Waters, Astrophys. J., Lett., 2001, 546, L127-L130.

21 J. Cernicharo, A. M. Heras, A. G. G. M. Tielens, J. R. Pardo, F. Herpin, M. Guélin and L. B. F. M. Waters, Astrophys. J., Lett., 2001, 546, L123-L126.

22 J. Bernard-Salas, E. Peeters, G. C. Sloan, J. Cami, S. Guiles and J. R. Houck, Astrophys. J., Lett., 2006, 652, L29-L32.

23 V. Wakelam, I. W. M. Smith, E. Herbst, J. Troe, W. Geppert, H. Linnartz, K. Öberg, E. Roueff, M. Agúndez, P. Pernot, H. M. Cuppen, J. C. Loison and D. Talbi, Space Sci. Rev., 2010, 156, 13-72.

24 J. P. Fonfría, J. Cernicharo, M. J. Richter and J. H. Lacy, Astrophys. J., 2011, 728, 43.

25 S. E. Malek, J. Cami and J. Bernard-Salas, Astrophys. J., 2012, 744, 16.

26 R. E. Bandy, C. Lakshminarayan, R. K. Frost and T. S. Zwier, Science, 1992, 258, 1630-1633.

27 R. E. Bandy, C. Lakshminarayan, R. K. Frost and T. S. Zwier, J. Chem. Phys., 1993, 98, 5362-5374.

28 R. K. Frost, G. S. Zavarin and T. S. Zwier, J. Phys. Chem., 1995, 99, 9408-9415. 
29 L. Bizzocchi, F. Tamassia, C. D. Esposti, L. Fusina, E. Cané and L. Dore, Mol. Phys., 2011, 109, 2181-2190.

30 M. Frenklach and E. D. Feigelson, Astrophys. J., 1989, 341, 372-384.

31 S. P. Ekern, A. G. Marshall, J. Szczepanski and M. Vala, J. Phys. Chem. A, 1998, 102, 3498-3504.

32 A. Krestinin, Combust. Flame, 2000, 121, 513-524.

33 M. E. Kress, A. G. Tielens and M. Frenklach, Adv. Space Res., 2010, 46, 44-49.

34 P. M. Woods, T. J. Millar, E. Herbst and A. A. Zijlstra, Astron. Astrophys., 2003, 402, 189-199.

35 N. Sakai and S. Yamamoto, Chem. Rev., 2013, 113, 8981-9015.

36 J. Cernicharo and M. Guélin, Astron. Astrophys., 1996, 309, L27-L30.

37 M. B. Bell, P. A. Feldman, M. J. Travers, M. C. McCarthy, C. A. Gottlieb and P. Thaddeus, Astrophys. J., Lett., 1997, 483, L61.

38 M. B. Bell, P. A. Feldman, J. K. G. Watson, M. C. McCarthy, M. J. Travers, C. A. Gottlieb and P. Thaddeus, Astrophys. J., 1999, 518, 740-747.

39 V. Vuitton, R. Yelle and M. McEwan, Icarus, 2007, 191, 722-742.

40 E. K. Plyler, E. D. Tidwell and T. A. Wiggins, J. Opt. Soc. Am., 1963, 53, 589-593.

41 K. F. Palmer, M. E. Mickelson and K. N. Rao, J. Mol. Spectrosc., 1972, 44, 131-144.

42 J. Pliva, J. Mol. Spectrosc., 1972, 44, 165-182.

43 J. Pliva, J. Mol. Spectrosc., 1972, 44, 145-164.

44 G. Guelachvili, A. Craig and D. Ramsay, J. Mol. Spectrosc., 1984, 105, 156-192.

45 N. L. Owen, C. H. Smith and G. A. Williams, J. Mol. Struct., 1987, 161, 33-53.

46 D. McNaughton and D. Bruget, J. Mol. Struct., 1992, 273, 11-25.

47 E. Arié and J. Johns, J. Mol. Spectrosc., 1992, 155, 195-204.

48 J. Vanderauwera, D. Hurtmans, M. Carleer and M. Herman, J. Mol. Spectrosc., 1993, 157, 337-357.

49 J. E. Gambogi, R. Z. Pearson, X. Yang, K. K. Lehmann and G. Scoles, Chem. Phys., 1995, 190, 191-205.

50 D. Zhao, K. D. Doney and H. Linnartz, J. Mol. Spectrosc., 2014, 296, 1-8.

51 M. A. Temsamani and M. Herman, J. Chem. Phys., 1995, 102, 6371-6384.

52 J. M. L. Martin, T. J. Lee and P. R. Taylor, J. Chem. Phys., 1998, 108, 676-691.

53 S. Thorwirth, M. E. Harding, D. Muders and J. Gauss, J. Mol. Spectrosc., 2008, 251, 220-223.

54 A. C. Simmonett, H. F. Schaefer III and W. D. Allen, J. Chem. Phys., 2009, 130, 044301.

55 K. Raghavachari, G. W. Trucks, J. A. Pople and M. Head-Gordon, Chem. Phys. Lett., 1989, 157, 479-483.

56 E. Bjarnov, D. Christensen, O. Nielsen, E. Augdahl, E. KlosterJensen and A. Rogstad, Spectrochim. Acta, Part A, 1974, 30, 1255-1262.

57 K. Matsumura, H. Kanamori, K. Kawaguchi, E. Hirota and T. Tanaka, J. Mol. Spectrosc., 1988, 131, 278-287.
58 D. McNaughton and D. Bruget, J. Mol. Spectrosc., 1991, 150, 620-634.

59 S. Haas, K. Yamada and G. Winnewisser, J. Mol. Spectrosc., 1994, 164, 445-455.

60 S. Haas, G. Winnewisser, K. Yamada, K. Matsumura and K. Kawaguchi, J. Mol. Spectrosc., 1994, 167, 176-190.

61 K. D. Doney, D. Zhao and H. Linnartz, J. Mol. Spectrosc., 2015, 316, 54-63.

62 C.-H. Chang, J. Agarwal, W. D. Allen and D. J. Nesbitt, J. Chem. Phys., 2016, 144, 074301.

63 K. W. Sattelmeyer and J. F. Stanton, J. Am. Chem. Soc., 2000, 122, 8220-8227.

64 F. Shindo, Y. Bénilan, P. Chaquin, J.-C. Guillemin, A. Jolly and F. Raulin, J. Mol. Spectrosc., 2001, 210, 191-195.

65 J. L. Toto, T. T. Toto, C. P. de Melo, B. Kirtman and K. Robins, J. Chem. Phys., 1996, 104, 8586-8592.

66 R. I. Kaiser, B. J. Sun, H. M. Lin, A. H. H. Chang, A. M. Mebel, O. Kostko and M. Ahmed, Astrophys. J., 2010, 719, 1884.

67 D. Zhao, J. Guss, A. J. Walsh and H. Linnartz, Chem. Phys. Lett., 2013, 565, 132-137.

68 T. J. Lee and G. E. Scuseria, in Quantum Mechanical Electronic Structure Calculations with Chemical Accuracy, ed. S. Langhoff, Kluwer Academic Publishers, Dordrecht, 1995.

69 R. J. Bartlett, in Modern Electronic Structure Theory, Part II, ed. D. R. Yarkony, World Scientific, Singapore, 1995.

70 J. Gauss and J. F. Stanton, Chem. Phys. Lett., 1997, 276, 70-77.

71 J. Gauss, in Encyclopedia of Computational Chemistry, ed. P. V. R. Schleyer, Wiley, New York, 1998.

72 L. McCaslin and J. F. Stanton, Mol. Phys., 2013, 111, 1492-1496.

73 D. E. Woon and T. H. Dunning Jr., J. Chem. Phys., 1995, 103, 4572-4585.

74 D. Feller, J. Comput. Chem., 1996, 17, 1571-1586.

75 K. L. Schuchardt, B. T. Didier, T. Elsethagen, L. Sun, V. Gurumoorthi, J. Chase, J. Li and T. L. Windus, J. Chem. Inf. Model., 2007, 47, 1045-1052.

76 A. A. Auer and J. Gauss, Phys. Chem. Chem. Phys., 2001, 3, 3001-3005.

77 K. L. Bak, J. Gauss, P. Jørgensen, J. Olsen, T. Helgaker and J. F. Stanton, J. Chem. Phys., 2001, 114, 6548-6556.

78 X. Zhang, A. T. Maccarone, M. R. Nimlos, S. Kato, V. M. Bierbaum, G. B. Ellison, B. Ruscic, A. C. Simmonett, W. D. Allen and H. F. Schaefer III, J. Chem. Phys., 2007, 126, 044312.

79 J. F. Stanton and J. Gauss, Int. Rev. Phys. Chem., 2000, 19, 61-95.

80 E. D. Simandiras, J. E. Rice, T. J. Lee, R. D. Amos and N. C. Handy, J. Chem. Phys., 1988, 88, 3187-3195.

81 J. Almlöf and P. R. Taylor, J. Chem. Phys., 1987, 86, 4070-4077.

82 C. W. Bauschlicher and P. R. Taylor, Theor. Chim. Acta, 1993, 86, 13-24.

83 J. M. L. Martin, P. R. Taylor and T. J. Lee, Chem. Phys. Lett., 1997, 275, 414-422. 
84 J. Vázquez and J. F. Stanton, Mol. Phys., 2007, 105, 101-109. 85 D. A. Matthews, J. Vázquez and J. F. Stanton, Mol. Phys., 2007, 105, 2659-2666.

86 Coupled-Cluster techniques for Computational Chemistry, a quantum-chemical program package by J. F. Stanton, J. Gauss, M. E. Harding, P. G. Szalay with contributions from A. A. Auer, R. J. Bartlett, U. Benedikt, C. Berger, D. E. Bernholdt, Y. J. Bomble, L. Cheng, O. Christiansen, F. Engel, R. Faber, M. Heckert, O. Heun, C. Huber, T.-C. Jagau, D. Jonsson, J. Jusélius, K. Klein, W. J. Lauderdale, F. Lipparini, D. A. Matthews, T. Metzroth, L. A. Mück, D. P. O’Neill, D. R. Price, E. Prochnow, C. Puzzarini, K. Ruud, F. Schiffmann, W. Schwalbach, C. Simmons, S. Stopkowicz, A. Tajti, J. Vázquez, F. Wang, J. D. Watts and the integral packages MOLECULE (J. Almlöf and P. R. Taylor), PROPS (P. R. Taylor), ABACUS (T. Helgaker, H. J. Aa. Jensen, P. Jørgensen, and J. Olsen), and ECP routines by
A. V. Mitin and C. van Wüllen. For the current version, 2017, see http://www.cfour.de.

87 F. Tamassia, E. Cane, L. Fusina and G. Di Lonardo, Phys. Chem. Chem. Phys., 2016, 18, 1937-1944.

88 R. Tay, G. F. Metha, F. Shanks and D. McNaughton, Struct. Chem., 1995, 6, 47-55.

89 P. Thaddeus, M. C. McCarthy, M. J. Travers, C. A. Gottlieb and W. Chen, Faraday Discuss., 1998, 109, 121-135.

90 Y. Kabbadj, M. Herman, G. D. Lonardo, L. Fusina and J. Johns, J. Mol. Spectrosc., 1991, 150, 535-565.

91 R. D’Cunha, Y. Sarma, G. Guelachvili, R. Farrenq, Q. Kou, V. Devi, D. Benner and K. N. Rao, J. Mol. Spectrosc., 1991, 148, 213-225.

92 J. Cernicharo, J. R. Goicoechea and E. Caux, Astrophys. J., Lett., 2000, 534, L199-L202.

93 E. E. Etim and E. Arunan, Astrophys. Space Sci., 2017, $362,4$. 